\title{
Reactions of the Immune System in Chronic Degenerative Neurological Diseases
}

\author{
P.L. McGeer, E.G. McGeer, T. Kawamata, T. Yamada and H. Akiyama
}

\begin{abstract}
Elements consistent with a cell mediated immune response were identified immunohistochemically in amyotrophic lateral sclerosis (ALS) spinal cord and Alzheimer disease (AD) hippocampus. T helper/inducer and cytotoxic/suppressor lymphocytes were detected in affected tissues in both diseases. In addition, abundant reactive microglia were found expressing the major histocompatibility glycoproteins HLA-A,B,C and HLA-DR, as well as receptors for the $\mathrm{Fc}$ chain $(\mathrm{Fc} \gamma \mathrm{Rl})$, for complement 3 and 4 , and for vitronectin. In $\mathrm{AD}$, the complement proteins $\mathrm{Clq}$, C4d, C3d and C5b-9 were found on dystrophic neurites, neuropile threads and some neurofibrillary tangles. In ALS, the only complement proteins identified were $\mathrm{C} 4 \mathrm{~d}$ and $\mathrm{C} 3 \mathrm{~d}$. The integrin ligands vitronectin and ICAM-1 were also identified in affected tissues in both diseases.

RÉSUMÉ: Réactions du système immunitaire dans les maladies neurodégénératives chroniques. Nous avons identifié par immunohistochimie des éléments compatibles avec une réponse immunitaire à médiation cellulaire dans la moelle épinière de patients atteints de sclérose latérale amyotrophique (SLA) et dans l'hippocampe de patients atteints de la maladie d'Alzheimer (MA). Des lymphocytes T auxiliaires/inducteurs et cytotoxiques/suppresseurs ont été détectés au niveau des tissus atteints dans les deux maladies. De plus, nous avons retrouvé une microglie réactive exprimant les glycoprotéines majeures d'histocompatibilité, HLA-A,B,C et HLA-DR, ainsi que les récepteurs pour la chaîne Fc (FcyRI), pour le complément 3 et 4, et pour la vitronectine. Dans la MA, les protéines du complément Clq, C4d, C3d et C5b-9 ont été obsersées sur les neurites dystrophiques, les neuropiles et certains amas neurofibrillaires. Dans la SLA, les seules protéines du complément identifiées étaient $\mathrm{C} 4 \mathrm{~d}$ et $\mathrm{C} 3 \mathrm{~d}$. Deux ligands, la vitronectine et ICAM-I, ont également été identifiés au niveau des tissus atteints dans les deux maladies.
\end{abstract}

Can. J. Neurol. Sci. 1991; 18: 376-379

Great strides have been made in the field of neuroscience during this century. Extensive information has become available concerning the functional neuroanatomy of the brain, the chemistry of the synapse, the electrophysiology of neurons, and the nature of drug-receptor interactions. However, almost no advances have been made in understanding the causes of neuronal death. As a result, there is no effective treatment, nor is there any method of preventing such universally fatal disorders as amyotrophic lateral sclerosis (ALS), Alzheimer disease (AD), Pick's disease, Shy-Drager syndrome, and a host of other chronic degenerative neurological disorders. These diseases have in common the premature death of neurons in selective brain areas, while other brain areas and peripheral organs are left relatively undisturbed.

The role of the immune system has not been systematically explored in these disorders. One reason may be the general belief that the brain is immunologically privileged. The existence of the blood/brain barrier, the absence of conventional lymphatic drainage, the failure of neurons to express MHC antigens, and the usual tolerance of brain to transplanted tissue have all reinforced this concept. Nevertheless, it is well known that the immune system responds to acute infections in the brain in much the same way as in other organs of the body. The same seems to be true for slow viral infections. Thus, the concept of immunological privilege, if it has validity at all, needs to be assessed in terms of the circumstances where it might apply.

In particular, the reactions which characterize chronic brain inflammation need to be carefully evaluated. Multiple sclerosis, and its experimental model, experimental allergic encephalitis, are the most studied chronic inflammatory states. These, however, involve a relapsing attack on a replaceable cell, the oligodendrocyte. Neurons are affected only secondarily. What about circumstances where neurons are the primary target? While there are models of acute neuronal death, especially from excitotoxins, there are not good models of chronic neuronal death apart from the slow virus disorders. Nevertheless, it is progressive and selective neuronal death which characterizes diseases such as AD and ALS. Do they represent a chronic inflammation of the brain? The only available approach is to investigate these diseases directly in terms of the presence of immune system cells and proteins, and to try and draw conclusions about the nature of the mechanisms involved. The reactions that need to

From the Kinsmen Laboratory of Neurological Research, Department of Psychiatry, University of British Columbia, Vancouver

Reprint requests to: Dr. Patrick L. McGeer, Kinsmen Laboratory of Neurological Research, Department of Psychiatry, University of B.C., Vancouver, British Columbia, Canada V6T IW5 
be distinguished are those generated by a persistent pathogen, those involving autoimmune attack, and those representing passive phagocytosis of neuronal debris. Such distinctions cannot easily be made, particularly when the various processes occur in combination. To assist in this process, we summarize here recent data from our laboratory on immunohistochemical staining of brain tissue using antibodies to various immune system proteins in two chronic degenerative neurological diseases: AD and ALS. In $A D$, cognitive functions are severely affected, while motor functions are relatively spared. In ALS, the reverse is true.

Antibodies to the following protein types were used: T-lymphocyte markers for helper/inducer (CD4) and cytotoxic/suppressor (CD8) classes; the leucocyte common antigen marker (LCA, CD45); the class I and class II major histocompatibility complex glycoproteins, HLA-A,B,C and HLA-DR; the complement proteins $\mathrm{Clq}, \mathrm{C} 3 \mathrm{~d}, \mathrm{C} 4 \mathrm{~d}$ and $\mathrm{C} 5 \mathrm{~b}-9$; the integrins LFA-1 (CD11a), complement receptor 3 (CR3, CD11b), complement receptor 4 (CR4, CDIlc), and vitronectin receptor; the integrin ligands intracellular adhesion molecule 1 (ICAM-1) and vitronectin (S protein); and the immunoglobulin receptor FcgRI (Table 1).

In chronic inflammatory states, the cell-mediated immune response is generally considered to be generated by T-lymphocytes. The antigens against which the immune response is to be directed are presented to T-lymphocytes by antigen presenting cells. The antigens presented are not full-size proteins; they are short peptides selected by the antigen presenting cell as being foreign and therefore worthy of immune system response. There are two requirements for $\mathrm{T}$ cells to recognize the antigen. The first is that it must be presented on a "platter" which is a special $\beta$ pleated segment of MHC glycoproteins." The second is that the particular peptide matches a $\mathrm{T}$ cell receptor for that conformation. ${ }^{2}$ Thus, a cell mediated immune response requires the presence of T-lymphocytes and MHC glycoproteins on antigen presenting cells. Table 1 shows that in both AD and ALS, Tlymphocytes of both the helper/inducer and cytotoxic/suppressor classes are present in affected tissue. Moreover, in both diseases abundant reactive microglia are present which express HLA-A, B, and C and HLA-DR. ${ }^{3-9}$ As previously reported, all capillary endothelial cells, whether in normal or affected brain areas, strongly express MHC class 1 antigens. ${ }^{4}$ Leucocyte common antigen is expressed moderately strongly by resting microglia, and very strongly by reactive microglia and all leucocytes. ${ }^{10}$ Thus, it reveals the presence of leucocytes marginating along capillary walls and infiltrating the tissue matrix in affected areas in both $\mathrm{AD}$ and $\mathrm{ALS}$. In addition to identifying resting microglia, it identifies reactive microglia by the intensity of the antigen-antibody reaction and changed morphology of the cells. LCA is one of many phenotypic markers linking microglia with blood monocytes and their tissue derivatives.

Complement proteins associated with the classical, but not the alternative, pathway are also found in $\mathrm{AD}^{11,12}$ and $\mathrm{ALS}^{8}$ tissue. The principal initiator of the classical pathway is an antigen-antibody complex to which $\mathrm{Cl}$ can bind, but trypsin-like proteins and heparin sulfate-type compounds can also start the cascade. C4 and C3 are cleaved, with the larger fragments chemically binding to tissue near the site of initiation. These fragments degrade, leaving tissue bound $\mathrm{C} 4 \mathrm{~d}$ and $\mathrm{C} 3 \mathrm{~d}$. These two complement proteins are a particularly revealing combination to detect in tissue. They are amplification products and thus are more readily detected than the initiating molecules. They are chemically bound products and not subject to dissociation.

Table 1: Antibody Staining of Alzheimer and Amyotrophic Lateral Sclerosis Tissue

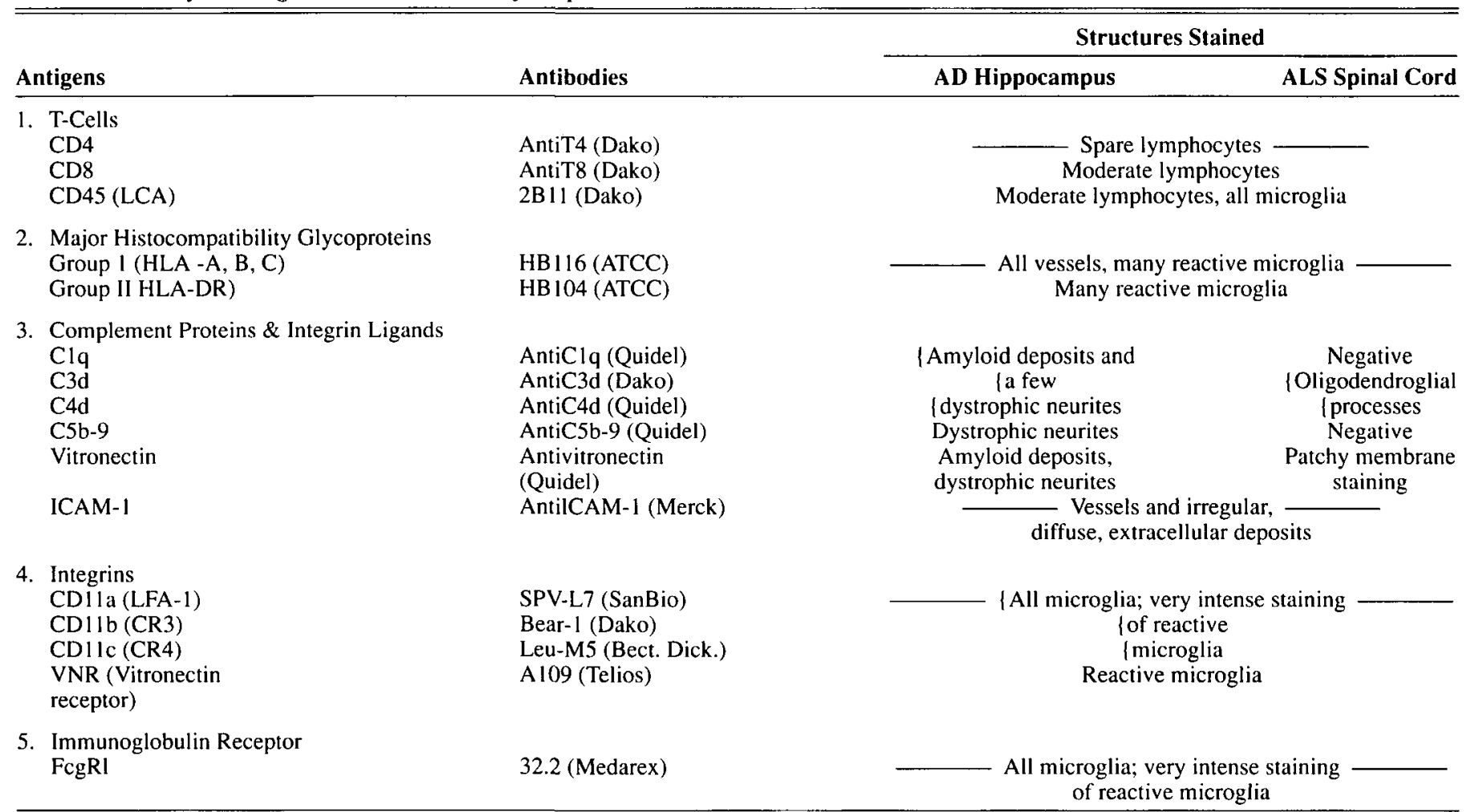


Finally, the presence of $\mathrm{C} 4$, which is not part of the alternative pathway, confirms that the classical pathway has been initiated. The chemically attached fragments opsonize the tissue, although it is not yet certain which parts bind to the $\beta-2$ integrin complement receptors. The remaining components $\mathrm{C} 5, \mathrm{C} 6, \mathrm{C} 7, \mathrm{C} 8$ and $\mathrm{C} 9$, can undergo a series of reactions culminating in the formation of the membrane attack complex, C5b-9. This can insert into lipid bilayers causing cell lysis. It is not intended for most membranes. Its purpose is to attack bacteria and other foreign cells. If host cells are inadvertently attacked, bystander lysis can occur. In $\mathrm{AD}$ tissue, antibodies to $\mathrm{Clq}, \mathrm{C} 3 \mathrm{~d}$ and $\mathrm{C} 4 \mathrm{~d}$ prominently stain amyloid deposits, dystrophic neurites, neuropile threads and some neurofibrillary tangles. " Antibodies to C5b-9 stain some dystrophic neurites, neuropile threads and neurofibrillary tangles, but not extracellular deposits." In ALS spinal cord, only staining for $\mathrm{C} 4 \mathrm{~d}$ and $\mathrm{C} 3 \mathrm{~d}$ has so far been detected, primarily on oligodendroglial processes. ${ }^{8}$ We have described these as complement activated oligodendroglia. ${ }^{13}$

The activators of complement reactions in AD and ALS are uncertain. Immunoglobulins have been reported in AD tissue 14 but the interpretation of this has been questioned. ${ }^{15}$ Anti-ganglioside antibodies in some ALS sera have been reported, with more than $50 \%$ of cases showing such antibodies in some studies; 16 this, however, is not a finding specific for ALS. Whether or not specific antibodies initiate the complement reactions in $\mathrm{AD}$ and ALS, immunoglobulin Fc receptors are present in abundance on all microglial cells. "The Fc $\gamma \mathrm{Rl}$ receptor levels are sharply increased on reactive microglia in these diseases. ${ }^{11,12}$ This receptor is highly localized to monocytes, establishing another link between monocytes and microglia.

Microglia constitutively express $\beta-2$ integrins, which are also known as leucocyte adhesion proteins. ${ }^{17}$ They too are upregulated when microglia become activated, and therefore can be observed in affected AD and ALS tissue. There are three members for the $\beta-2$ family: LFA-1 (CDIla), and the complement receptors CR3 (CD11b) and CR4 (CD11c). The ligand for LFA-1 is ICAM-1. ICAM-1 staining of all capillaries is observed in normal tissue since it is produced by endothelial cells. In affected AD and ALS tissue, there is patchy, diffuse staining of the extracellular matrix, suggesting the possibility of chemotactic guidance to some areas of pathology.

Vitronectin, otherwise known as complement S-protein, binds to C5b-9. In the soluble state, this binding inhibits insertion of the membrane attack complex. However, it also binds to the complex when inserted, and in this situation it may act as an opsonizer for the vitronectin receptor. This receptor is an unusual integrin in that the subunit may be associated with more than one B subunit. 18 Vitronectin is normally found in serum, and thus staining for it is found in vessels containing residual plasma. Staining for vitronectin is also found on plaques and tangles in AD tissue ${ }^{18}$ and on some membranes in ALS spinal cord. ${ }^{8}$ The vitronectin receptor is upregulated on reactive microglia in both AD and ALS.

Figure 1 illustrates some of the potential biochemical interactions between damaged neurons and activated microglial cells. A microglial cell is shown with some of its established receptors. These are presumably for the purpose of binding the cell to targets in the extracellular space or on membranes of other cells to facilitate chemotactic guidance and phagocytosis. Ligands of

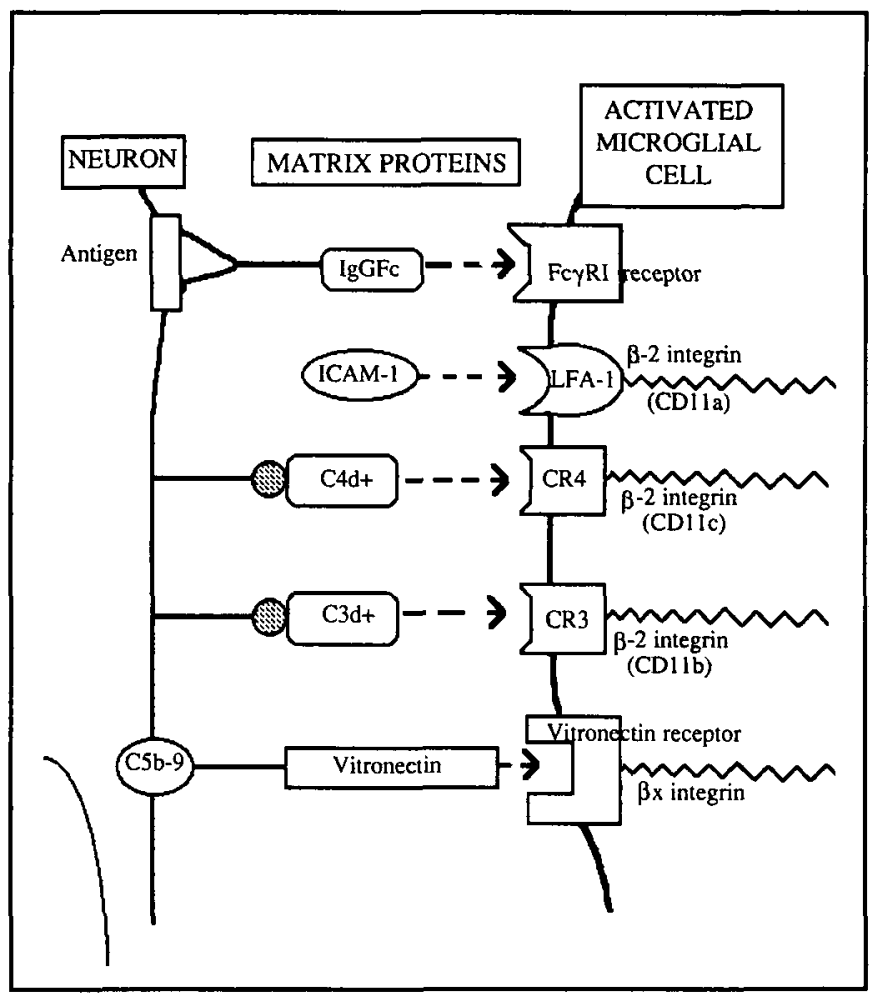

Figure 1 - Possible interactions between activated microglial cell receptors, extracellular proteins and membranes of damaged neuronal cells.

three of these receptors, C4d, C3d and vitronectin, were found attached to damaged neurons, in addition to extracellular debris, in $\mathrm{AD}$. The membrane attack complex was found on neuronal tissue only in AD.

T-lymphocytes were found in affected areas in both $A D$ and ALS, as were reactive microglia expressing high levels of MHC glycoproteins. These data are all consistent with the presence of a cell mediated immune response in both diseases, although the reasons for its initiation remain unclear.

\section{ACKNOWLEDGEMEN'T}

We thank Ms Joane Sunahara for technical assistance. This research was supported by grants from the Medical Research Council of Canada, the American Health Assistance Foundation, and the Alzheimer Society of British Columbia, as well as donations from individual British Columbians.

\section{REFERENCES}

1. Bjorkman PJ, Saper MA, Samraoui B, et al. Structure of the human class 1 histocompatibility antigen, HLA-A2. Nature 1987; 329: 506-512.

2. Stites DP, Stobo JD and Wells JV. Basic and Clinical Immunology, 6th ed. Norwalk, Appleton \& Lange 1987.

3. McGeer PL, Itagaki S and McGeer EG. Expression of the histocompatibility glycoprotein HLA-DR in neurological disease. Acta Neuropathol 1988; 76: 550-557.

4. Tooyama I, Kimura H, Akiyama H, et al. Reactive microglia express class I and class II major histocompatibility complex antigens in Alzheimer disease. Brain Res. 1990; 523: 273-280.

5. Rogers J, Luber-Narod J, Styren SD, et al. Expression of immune system-associated antigen by cells of the human central nervous 
system. Relationship to the pathology of Alzheimer's disease. Neurobiol Aging 1988; 9: 330-349.

6. Styren SD, Civin WH and Rogers J. Molecular, cellular and pathologic characterization of HLA-DR immunoreactivity in normal elderly and Alzheimer's disease brain. Exp Neurol 1990; 110: 93-104.

7. Perlmutter LS, Barron E and Chui HC. Morphologic association between microglia and senile plaque amyloid in Alzheimer's disease. Neurosci Lett 1990; 199: 32-36.

8. Kawamata $T$, Akiyama $H$, Yamada $T$, et al. Immunological reactions in amyotrophic lateral sclerosis brain and spinal cord. Soc Neurosci Abstr 1990; 16: 1344.

9. Lampson LA, Kushner PD and Sobel RA. Major histocompatibility complex antigen expression in the affected tissues in amytrophic lateral sclerosis. Ann Neurol 1990; 28: 365-372.

10. Itagaki S, McGeer PL and Akiyama $H$. Presence of T-cytotoxic suppressor and leucocyte common antigen positive cells in Alzheimer's disease brain tissue. Neurosci Lett 1988; 91: 259-264.

11. McGeer PL, Akiyama H, Itagaki S, et al. Immune system response in Alzheimer's disease. Can J Neurol Sci 1989; 16: 516-527.

12. Eikelenboom P, Hack CE, Rozemuller JM, et al. Complement activation in amyloid plaques in Alzheimer's dementia. Virchows Arch (Cell Pathol) 1989; 56: 259-262.
13. Yamada T, Akiyama $\mathrm{H}$ and McGeer PL. Complement-activated oligodendroglia: a new pathogenic entity identified by immunostaining with antibodies to human complement proteins $\mathrm{C} 3 \mathrm{~d}$ and C4d. Neurosci Letter 1990; 112: 161-166.

14. Ishii $T$ and Haga S. Immuno-electron microscopic localization of immunoglobulins in amyloid fibrils of senile plaques. Acta Neuropathol (Berlin) 1976; 20: 372-378.

15. Eikelenboom $P$ and Stam FC. Immunoglobulins and complement factors in senile plaques. Acta Neuropathol (Berlin) 1982; 57: 239-242.

16. Pestronk A, Adams RN, Lawson L, et al. Serum antibodies to GMl ganglioside in amyotrophic lateral sclerosis. Neurology 1988; 38: $1457-1461$.

17. Akiyama $\mathrm{H}$ and McGeer PL. Brain microglia constitutively express $\beta 2$ integrins. J Neuroimmunol 1990; 30: 81-93.

18. Akiyama H, Kawamata $T$, Dedhar $S$, et al. Immunohistochemical localization of vitronectin, its receptor and beta-3 integrin in Alzheimer brain tissue. J Neuroimmunol 1991; 32: 19-28. 